Article

\title{
Exploring the Expression of Cardiac Regulators in a Vertebrate Extremophile: The Cichlid Fish Oreochromis (Alcolapia) alcalica
}

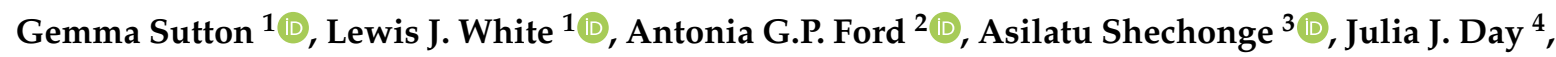 \\ Kanchon K. Dasmahapatra ${ }^{1}$ and Mary E. Pownall ${ }^{1, * \text { (D) }}$ \\ 1 Biology Department, University of York, York YO10 5DD, UK; gs569@exeter.ac.uk (G.S.); \\ ljw569@york.ac.uk (L.J.W.); kanchon.dasmahapatra@york.ac.uk (K.K.D.) \\ 2 Department of Life Sciences, Centre for Research in Ecology, Whitelands College, University of Roehampton, \\ Holybourne Avenue, London SW15 4JD, UK; Antonia.Ford@roehampton.ac.uk \\ 3 Tanzania Fisheries Research Institute, P.O.BOX 98 Kyela, Mbeya, Tanzania; ashechonge@yahoo.com \\ 4 Department of Genetics, Evolution and Environment, University College London, Darwin Building, Gower \\ Street, London WC1E 6BT, UK; j.day@ucl.ac.uk \\ * Correspondence: betsy.pownall@york.ac.uk; Tel.: +44-1904-328692
}

Received: 2 September 2020; Accepted: 30 September 2020; Published: 4 October 2020

\begin{abstract}
Although it is widely accepted that the cellular and molecular mechanisms of vertebrate cardiac development are evolutionarily conserved, this is on the basis of data from only a few model organisms suited to laboratory studies. Here, we investigate gene expression during cardiac development in the extremophile, non-model fish species, Oreochromis (Alcolapia) alcalica. We first characterise the early development of $O$. alcalica and observe extensive vascularisation across the yolk prior to hatching. We further investigate heart development by identifying and cloning $O$. alcalica orthologues of conserved cardiac transcription factors gata4, tbx5, and mef $2 c$ for analysis by in situ hybridisation. Expression of these three key cardiac developmental regulators also reveals other aspects of $O$. alcalica development, as these genes are expressed in developing blood, limb, eyes, and muscle, as well as the heart. Our data support the notion that $O$. alcalica is a direct-developing vertebrate that shares the highly conserved molecular regulation of the vertebrate body plan. However, the expression of gata4 in O. alcalica reveals interesting differences in the development of the circulatory system distinct from that of the well-studied zebrafish. Understanding the development of O. alcalica embryos is an important step towards providing a model for future research into the adaptation to extreme conditions; this is particularly relevant given that anthropogenic-driven climate change will likely result in more freshwater organisms being exposed to less favourable conditions.
\end{abstract}

Keywords: cichlid fish; extremophile; environmental adaptation; cardiac myogenesis

\section{Introduction}

Aquatic ectotherms, such as fish, are significantly impacted by the changes or stressors in their environment, as they rely on the surrounding water for maintaining homeostasis $[1,2]$. Despite this restriction, fish have evolved morphological, biochemical, physiological, behavioural, and developmental mechanisms allowing them to colonise nearly all aquatic environments, including a variety of extreme habitats [3,4]. Although most fish species are unable to survive extremes of temperature, $\mathrm{pH}$, salinity, and environments which seasonally dry out, some specialised species have adapted to thrive in such conditions, making them useful subjects for studying the molecular and developmental mechanisms underpinning adaptation to imposed stressors [5]. Exploring the naturally evolved adaptations in extremophile vertebrates will give insight into core biological 
functions, which may provide important information for future research in vertebrate biology, as well as the diversity in animal development, and it may even contribute to our understanding of human disease [6-8].

Knowledge of development is key for understanding mechanisms of evolutionary variation, as changes in developmental processes can result in novel phenotypes [9]. Currently, the majority of knowledge of early ontogeny of fishes stems from studies in the model organisms zebrafish (Danio rerio) and medaka (Oryzias latipes) [10,11]. These species were selected as suitable model organisms for developmental biology due to their size, short development periods, accessible genetic tools, and ability to be bred and reared easily in laboratory conditions. However, these selected teleosts may not be representative of early development in other fish species. The study of development in non-model species has the potential to provide additional insights into the molecular evolution of biological diversity in teleosts which are by far the most species-rich vertebrate clade. The Teleostei comprise ca. 34,000 species, accounting for nearly $98 \%$ of all actinopterygian (ray-finned) fishes, i.e., half of all extant vertebrates [12]. Research using non-model organisms will allow wider species comparisons and a better understanding of adaptive traits [13].

With their high species richness and recent adaptive radiations, cichlid fishes are a model system in evolutionary biology, particularly for studying speciation [14-16]. One subgenus, Alcolapia (nested within the genus Oreochromis [17]), presents a unique radiation of extremophile cichlids, inhabiting the extreme waters of the East African soda lakes of Natron and Magadi. This adaptive radiation comprises four described species, Oreochromis (Alcolapia) alcalica, O. (A.) latilabris, O. (A.) ndalalani (Lake Natron, Tanzania), and O. (A.) grahami (Lake Magadi, Kenya), and diverged as recently as 10,000 years ago from freshwater ancestors [18-20]. The Alcolapia fish experience water temperatures of $30-42{ }^{\circ} \mathrm{C}, \mathrm{pH} 9-11.5$, fluctuating dissolved oxygen levels $(0.08-6.46 \mathrm{mg} / \mathrm{L})$, and high salt concentrations ( $>20 \mathrm{ppt}$ ) [21]. Living in this environment has led to a number of key adaptations including $100 \%$ ureotelism, facultative airbreathing, a specialised gut morphology, and maintaining a heightened metabolic rate [22-27]

An aspect of development that shows striking conservation across animals with very different lifestyles, from insects to fish to tetrapods, is that of heart function to pump fluid around the body, transporting nutrients, metabolites, and oxygen to tissues [28-30]. How this remarkable adaptation develops during embryogenesis has been studied in several experimental model organisms, providing an understanding of conserved mechanisms of cardiac development in vertebrates [28]. As the primary teleost model organism, zebrafish has emerged as an important vertebrate model for studying cardiovascular development and disease [31].

Cardiac myogenesis in zebrafish begins with the emergence of cardiac progenitor cells at $5 \mathrm{~h}$ post fertilisation (hpf) in the lateral marginal zone of the blastula, with ventricular progenitors situated more dorsally and closer to the margin than atrial progenitors [32,33]. During gastrulation, the cardiac progenitors migrate to the anterior lateral plate mesoderm where bilateral progenitors fuse into the cardiac disc with endocardial cells in the centre, surrounded by ventricular cardiomyocytes, surrounded by atrial cardiomyocytes that elongate into the linear heart tube. By $24 \mathrm{hpf}$, heart tube contraction initiates $[34,35]$ and the linear heart tube undergoes cardiac jogging, whereby left-right symmetry is broken as the heart tube migrates leftwards and begins looping [36]. At $48 \mathrm{hpf}$, the two-chambered heart is clearly distinguishable by the constriction of the atrioventricular canal [37].

The network of cardiac transcription factors that regulate embryonic heart development displays a high degree of evolutionary conservation across vertebrates; here, we identify and describe the expression of a subset of these regulators, GATA-binding protein 4 (GATA4), T-box 5 (Tbx5), and Myocyte enhancer factor 2c (Mef2c) in Oreochromis (Alcolapia) alcalica. Members of the GATA family of zinc-finger transcription factors are involved in the early specification of cardiac progenitors. The GATA factors are crucial during haematopoiesis and cardiac myogenesis in vertebrates and Drosophila $[38,39]$. Tbx5 is a member of the T-box family of transcription factors and is expressed during development of heart, eyes, and forelimbs. Mutations in TBX5 in humans cause Holt-Oram syndrome (HOS), an autosomal-dominant disorder characterised by forelimb malformations and 
cardiac defects [40-42]. Cardiac abnormalities of HOS patients include septation defects and conduction disease [43]. Myocyte enhancer factor 2 (Mef2) proteins are MADs (MCM1, Agamous, Deficiens, Serum response factor)-box transcription factors. There are four vertebrate mef 2 genes, mef $2 a-d$, expressed in precursors of heart, skeletal, and smooth muscle lineages [44]. Loss of function of the single mef2 gene in Drosophila results in abnormal development of all muscle types, including cardiomyocytes [45]. In mice, Mef $2 a, c$, and $d$ are expressed in cardiac mesoderm and Mef2a- or Mef2c-null mice display cardiac developmental defects [46].

We report here methods to acquire and culture Oreochromis (Alcolapia) alcalica embryos and to interrogate gene expression patterns using whole-mount in situ hybridisation. We present the first developmental stage series of $O$. alcalica and the expression patterns of the O. alcalica orthologues of the cardiac regulatory genes gata4, $t b \times 5$, and $m e f 2 c$ as assessed by in situ hybridisation.

\section{Methods}

Live specimens of $O$. alcalica were collected from a single spring (site 5) [20,47] at Lake Natron in Tanzania (permit 2017-259- NA-2011-182) in June 2017. Fish were packaged individually in breather bags and transported to Bangor University to establish a breeding colony. Some of the O. alcalica specimens were subsequently moved to the University of York and housed in a recirculating aquarium (Aquatics Habitat) with constant water conditions kept at a temperature of $30^{\circ} \mathrm{C}, \mathrm{pH}$ 9, and conductivity of $3800 \mu \mathrm{S}$. A separate zebrafish system was maintained at $27^{\circ} \mathrm{C}, \mathrm{pH} 7.4$, and conductivity $800 \mu \mathrm{S}$. This study was carried out using procedures authorised by the United Kingdom (UK) Home Office in accordance with the Animals Scientific Procedures Act (1986) and approved by the Animal Welfare and Ethical Review Body at the University of York and the UK Home Office project licence to MEP (POF245295).

\subsection{Fish maintenance and Embryo Collection}

To control $O$. alcalica breeding, dividers were placed in tanks to separate a single male from a group of 3-4 females. After acclimatising for several days, dividers were removed and mating behaviour proceeded. O. alcalica is a mouth-brooding cichlid, in which females carrying fertilised eggs are identified by an enlarged buccal cavity. To obtain embryos, the females were removed from the water, and embryos were released by applying light pressure to the buccal cavity. After collection, O. alcalica embryos were incubated at $29-30^{\circ} \mathrm{C}$ gently shaking in system water with fungicide methylene blue $(0.0003 \mathrm{mg} / \mathrm{mL})$ (Sigma). Zebrafish (AB) embryos were collected as per standard procedures. At specific stages, O. alcalica and zebrafish embryos were dechorionated and fixed for $1 \mathrm{~h}$ at room temperature in MEMFA (0.1 M 3-(N-Morpholino)propanesulfonic acid (MOPS), pH 7.4, 2 mM Ethylene glycol tetraacetic acid (EGTA), $1 \mathrm{mM} \mathrm{MgSO}_{4}, 3.7 \%$ formaldehyde) and stored at $-20{ }^{\circ} \mathrm{C}$ in $100 \%$ methanol.

\subsection{Phylogeny}

Zebrafish gata4, tbx5, and mef2c coding sequences were identified on ZFIN (https://zfin.org/). BLAST (https://blast.ncbi.nlm.nih.gov/Blast.cgi) was used to identify these sequences in the published genome of the freshwater cichlid Oreochromis niloticus. Oreochromis niloticus sequences were aligned to the unpublished O. alcalica genome (Dashamapatra, in preparation) to identify O. alcalica coding sequences of the cardiac regulators; we found these putative orthologues to have $60 \%$ (Tbx5), $63 \%$ (Mef2c), and 62\% (GATA4) amino-acid sequence identity with the zebrafish proteins. The gata4, tbx5, and mef2c sequences were retrieved from Drosophila melanogaster, Takifugu rubripes, Maylandia zebra, Nothobranchus furzeri, Oryzias latipes, Danio rerio, Callorhinchus milii, Xenopus tropicalis, Gallus gallus, Mus musculus, Pan troglodytes, and Homo sapiens using BLAST. The predicted full-length amino-acid sequence was deduced from the coding sequence of each gene, and multiple sequence alignment was conducted using MEGA-X by MUSCLE (Robert C. Edgar, 2004; codon alignment). Phylogenetic tree reconstruction was conducted in MEGA- $X$ on individual genes using maximum likelihood [48]. The tree with the highest $\log$ likelihood is presented in Figures 2-4. The percentage of trees in which 
the associated taxa clustered together is shown next to the branches. Initial trees for the heuristic search were obtained automatically by applying Neighbour-Join and BioNJ algorithms to a matrix of pairwise distances estimated using a Jones-Taylor-Thornton (JTT) model, and then selecting the topology with a superior log likelihood value. A discrete Gamma distribution was used to model evolutionary rate differences among sites, and a tree was drawn to scale, with branch lengths measured in the number of substitutions per site.

\subsection{RNA Extraction, Complementary DNA (cDNA) Synthesis, and Reverse-Transcription PCR (RT-PCR)}

RNA was extracted from O. alcalica and zebrafish embryos using TRI Reagent (Sigma-Aldrich) using phase separation and isopropanol precipitation. Here, $1 \mu \mathrm{g}$ of total RNA was used for cDNA synthesis with Superscript IV (Invitrogen) and random hexamers (Thermo Scientific). Primers (Sigma) for the amplification of $O$. alcalica cardiac regulatory genes were designed against sequences identified in the O. alcalica genome using PrimerSelect (DNASTAR) (Table 1) to amplify regions of 400-600 bp in length; a similar approach was used for zebrafish orthologues using sequences in NCBI. The cDNAs were amplified by RT-PCR, cloned into pGEM T-Easy (Promega), and sequenced. The following sequences were submitted to Genbank: Oa tbx5 (MT904199), Oa mef2c (MT904200), and Oa gata4 (MT904201). For generating antisense RNA probes, SalI (Promega) linearised plasmids were used as templates for T7 transcription (Ambion), and NcoI (Promega) linearised plasmids were used as templates for SP6 transcription (Ambion), depending on orientation of the insert. In vitro run-off transcription at $37^{\circ} \mathrm{C}$ was used to incorporate digoxigenin (DIG)-labelled UTP analogue (Roche).

Table 1. Oreochromis (Alcolapia) alcalica and zebrafish primers for RT-PCR and probe synthesis.

\begin{tabular}{|c|c|c|}
\hline Gene & Forward Primer $5^{\prime}-3^{\prime}$ & Reverse Primer $5^{\prime}-3^{\prime}$ \\
\hline O. alcalica gata4 & TGTCTCCGCGCTTCACCTTCTCCA & GACCGGCTCTCCCTCTGCGTTCC \\
\hline O. alcalica mef $2 c$ & ATGGGGCGAAAGAAGAT & AGCCCACCCTGATTACTG \\
\hline O. alcalica tbx5 & AGAGGCAGCGACGACAATGAGC & GGGGGATAGGAGGAGGGGTGATAG \\
\hline Zebrafish gata4 & CCTACAGGCACCCCAGCAGAGCAG & CCCGCCGCCACAGAGGAGTC \\
\hline Zebrafish mef $2 \mathrm{ca}$ & TTGCGCGGATAATGGACGAACG & GGGGGCCGGTGGGTGACTC \\
\hline Zebrafish $t b x 5 b$ & GCTCCCCGCCACTACAAACTCAG & GATATGTCCGAAAGGGTCCAGGTG \\
\hline
\end{tabular}

\subsection{Whole-Mount In Situ Hybridisation}

Fixed embryos were rehydrated with washes of decreasing levels of methanol/phosphate-buffered saline-Tween-20 (PBSAT) (75\% methanol/PBSAT, 50\% methanol/PBSAT, 100\% PBSAT) and treated with $10 \mu \mathrm{g} / \mathrm{mg}$ proteinase $\mathrm{K}$ (Roche) at room temperature. Zebrafish embryos were treated with proteinase $\mathrm{K}$ for $10 \mathrm{~min}$ per day post fertilisation (dpf). O. alcalica embryos of $2 \mathrm{dpf}, 3 \mathrm{dpf}$, and $7 \mathrm{dpf}$ were treated with proteinase $\mathrm{K}$ for 4, 15, and $30 \mathrm{~min}$, respectively. Embryos were treated with $0.1 \mathrm{M}$ triethanolamine/acetic anhydride and washed in PBSAT. Following post-fixation with $10 \%$ formalin and $2 \mathrm{~h}$ incubation at $68^{\circ} \mathrm{C}$ in hybridisation buffer (50\% formamide (Ambion), $1 \mathrm{mg} / \mathrm{mL}$ total yeast RNA, $5 \times$ saline-sodium citrate (SSC), $100 \mu \mathrm{g} / \mathrm{mL}$ heparin, $1 \times$ Denharts, $0.1 \%$ Tween-20, $0.1 \%$ CHAPS, $10 \mathrm{mM}$ EDTA), embryos were incubated in $1 \mathrm{~mL}$ of hybridisation buffer with $3-6 \mu \mathrm{L}$ of DIG-labelled antisense probe at $68^{\circ} \mathrm{C}$ overnight.

Embryos were extensively washed at $68^{\circ} \mathrm{C}$ in $2 \times$ SSC $+0.1 \%$ Tween-20, $0.2 \times$ SSC $+0.1 \%$ Tween-20, and maleic acid buffer (MAB; $100 \mathrm{mM}$ maleic acid, $150 \mathrm{mM} \mathrm{NaCl}, 0.1 \%$ Tween-20, pH 7.8). This was replaced with pre-incubation buffer ( $4 \times \mathrm{MAB}, 10 \% \mathrm{BMB}, 20 \%$ heat-treated lamb serum) for $2 \mathrm{~h}$. Embryos were incubated overnight (rolling at $4{ }^{\circ} \mathrm{C}$ ) with fresh pre-incubation buffer and 1/2000 dilution of anti-DIG coupled with alkaline phosphatase (AP) (Roche). Embryos were washed in $1 \times \mathrm{MAB}$ and AP buffer (100 mM Tris, $50 \mathrm{mM} \mathrm{MgCl}, 100 \mathrm{mM} \mathrm{NaCl}, 0.1 \%$ Tween-20). BM purple (Roche), the substrate for $\mathrm{AP}$, was applied to embryos and left at room temperature until colour developed. Embryos were fixed in MEMFA and photographed. The 7dpf gata 4 embryos were washed in PBSAT and bleached in $5 \% \mathrm{H}_{2} \mathrm{O}_{2}$ (Merck) under bright light to remove pigmentation. Once bleached, embryos were 
washed in PBSAT and stored in MEMFA. Stack images of the in situ hybridisations were taken using a SPOT Camera (14.2 Colour Mosaic, Diagnostic Instruments). Focus stacking and image editing was undertaken on Adobe Photoshop 2020.

\section{Results}

\subsection{Early Development of O. alcalica}

The early development of $O$. alcalica during the first $10 \mathrm{dpf}$ at $28^{\circ} \mathrm{C}$ is documented in Figure 1 . Embryonic development could be subdivided into six periods: zygote (Figure 1A), cleavage (Figure 1B), blastula-gastrula (Figure 1C,D), segmentation (Figure 1E), pharyngula (Figure 1F-H), and hatching (Figure 1G). Oreochromis (Alcolapia) alcalica's embryonic development is similar to that of other mouth-brooding cichlids [49-51]. The embryo was surrounded by the chorion, a transparent membrane that stuck closely to the egg which persisted until hatching (Figure 1A-H). The yolk was opaque yellow and homogeneous in appearance, making observations of the embryonic anlage difficult. At early embryonic stages, there was almost no perivitelline space between the chorion and yolk, and dechorionation was difficult without puncturing the yolk (Figure 1A-D).

Newly fertilised eggs of $O$. alcalica had an ovoid shape, with the animal pole narrower than the vegetal pole (Figure 1A). The blastodisc sat at the animal pole. The first cleavage furrow was meridional and occurred at $2 \mathrm{hpf}$, resulting in two blastomeres (Figure 2B). The further mitotic divisions that occur during the cleavage period resulting in many blastomeres were not distinguishable under a dissecting microscope. Furthermore, the specific timing and cellular dynamics of $O$. alcalica gastrulation were difficult to observe due to the yolk (Figure 1C,D). Epiboly was previously described in Nile tilapia, Oreochromis niloticus, another mouth-brooding cichlid that is closely related to O. alcalica [17], by sequential fixation of blastula-gastrula stage embryos [49]. As O. alcalica embryos dissociated rapidly when dechorionated and fixed before the segmentation stage, we were unable to document gastrulation in $O$. alcalica in this study.

By $42 \mathrm{hpf}$, the $O$. alcalica embryos completed gastrulation and entered segmentation period (Figure 1E). At $66 \mathrm{hpf}$, the embryos entered the pharyngula period. Melanocytes emerged from the embryonic axis and began migrating across the yolk. Embryos had a clearly formed head with unpigmented eyes (Figure 1F). At this stage, a linear heart tube formed, and rhythmic contractions could be observed (Supplementary Movie A). At $3 \mathrm{dpf}$, the head developed upwards from the yolk. Early vasculature development was observed in patches on the yolk and around the heart (Figure 1G). This early vasculature was pumped across the yolk, through the heart tube and embryo (Supplementary Movie B). By 4 dpf, the eyes developed pigmentation, the heart started to loop, and extensive vasculature developed across the yolk (Figure $1 \mathrm{H}$, Supplementary Movie C). At $5 \mathrm{dpf}$, embryos hatched from the chorion membrane (Figure 1I). At 5-6 dpf, the heart looping was complete and the two-chambered heart formed (Figure 1I-J, Supplementary Movie D). After hatching, many aspects of the adult body plan were apparent, and embryos could swim actively by $7 \mathrm{dpf}$ (Figure 1J-M).

O. alcalica rapidly develops adult morphology without a prolonged, free-feeding larval stage [49,51] and, therefore, fits the definition of a direct-developing fish species which have large, yolk-rich eggs and complete their development while living off the maternally deposited yolk supply, until transforming directly into a free-feeding juvenile [52,53]. 


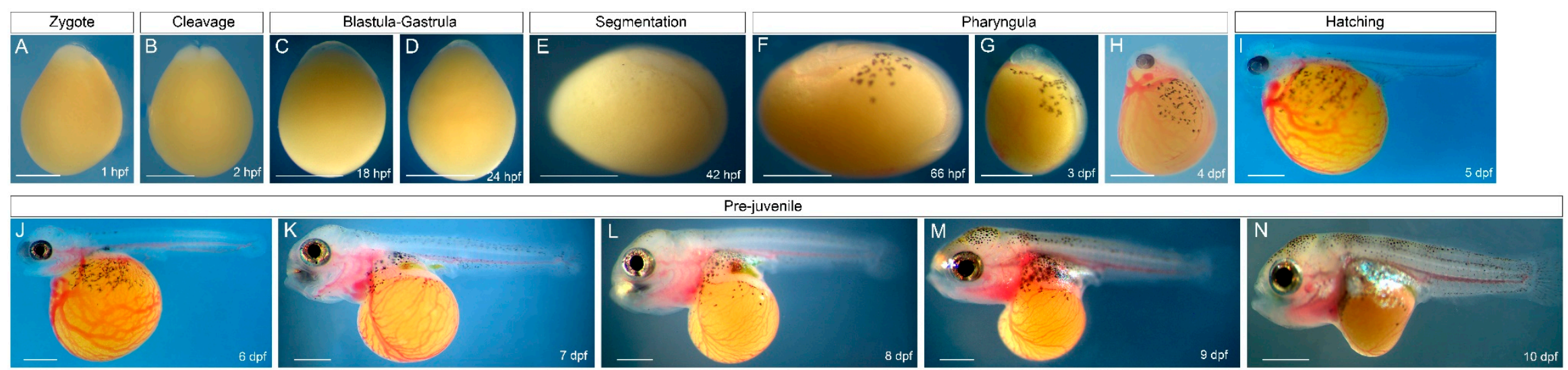

Figure 1. Embryonic and pre-juvenile development of Oreochromis (Alcolapia) alcalica. (A) At $1 \mathrm{~h}$ post fertilisation (hpf), O. alcalica embryos were ovoid in shape with the embryonic region located at the animal pole, on top of the large yellow yolk. (B) At $2 \mathrm{hpf}$, the first cell division occurred and two blastomeres were observed. (C,D) The embryo underwent gastrulation (18 hpf-24 hpf). The cellular dynamics of $O$. alcalica gastrulation were not easily observed due to the large yellow yolk. (E) Gastrulation was completed by $42 \mathrm{hpf}$. The antero-posterior axis could be distinguished, and the neural tube formed. (F) At $66 \mathrm{hpf}$, the antero-posterior axis elongated further. Pigmented melanocytes of the neural crest lineage emerged from the embryonic axis. A clear head and unpigmented eye could be distinguished. (G) By 3 days post fertilisation (dpf), there was an increased number of melanocytes migrating on the yolk. The embryo began to vascularise in patches on the yolk and in the area of the beating heart. (H) At $4 \mathrm{dpf}$, the vascular system extended across the yolk and a clearly beating heart was visible with strong blood circulation. The eye developed pigmentation. (A-H) Throughout these stages, the embryo was surrounded by the chorion membrane. (I) At 5 dpf, embryos hatched from the chorion. (J-N) Following hatching at 6-10 dpf, the yolk decreased in size and embryos rapidly developed adult morphology. (A-D) Animal pole to the top. $(\mathbf{E}, \mathbf{F}, \mathbf{I}-\mathbf{N})$ Lateral views; anterior to the left. $(\mathbf{G}, \mathbf{H})$ Lateral views; anterior to the top. Scale bars correspond to $1 \mathrm{~mm}$. Heart contraction was observed and recorded at 66 hpf, 3 dpf, 4 dpf, and 5 dpf (see Supplementary Movies Supplementary A-D). 

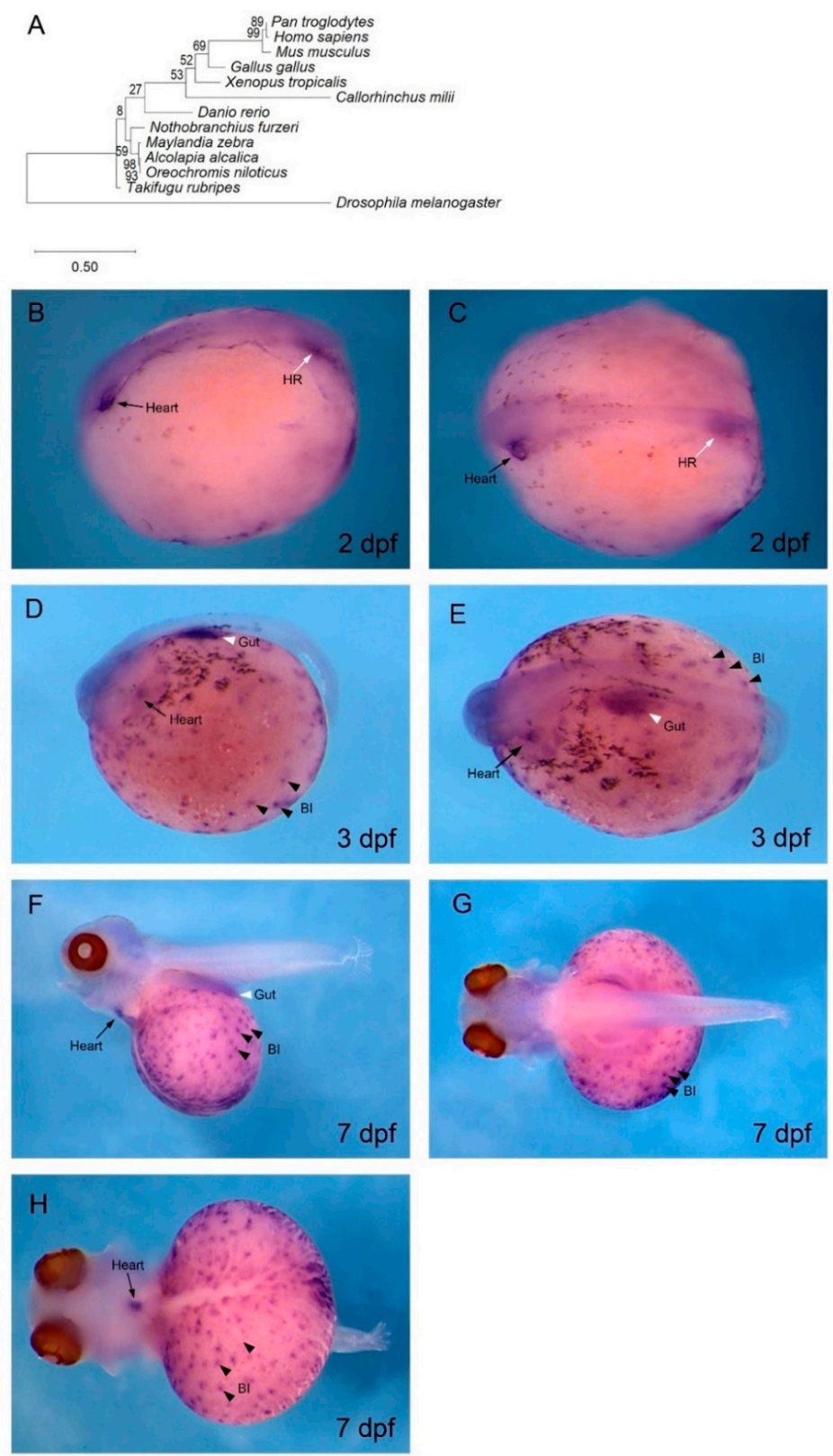

Figure 2. gata4 is expressed in cardiac and vascular regions of O. alcalica embryos. (A) Phylogenetic analysis of GATA4. The evolutionary history was inferred using the maximum likelihood method and Dayhoff with frequency model and gamma distribution [58]. (B-H) In situ hybridisation of O. alcalica gata4 at 2 days post fertilisation (dpf) (B,C), $3 \mathrm{dpf}(\mathbf{D}, \mathbf{E})$, and $7 \mathrm{dpf}(\mathbf{F}-\mathbf{H})$. At $2 \mathrm{dpf}$, Oa gata4 was expressed in the heart and haematopoietic region (HR) (B,C). At $3 \mathrm{dpf}$ and $7 \mathrm{dpf}$, Oa gata4 was expressed in the heart, gut, and blood islands (BI) (D-H). At $7 \mathrm{dpf}$, embryos were bleached to remove melanocyte pigmentation $(\mathbf{F}-\mathbf{H})$. Black arrows denote the heart, black arrowheads mark blood islands (BI), white arrows denote the haematopoietic region (HR), and white arrowheads mark the gut. $(\mathbf{B}, \mathbf{D}, \mathbf{F})$ Lateral views; anterior to the left. $(\mathbf{C}, \mathbf{E}, \mathbf{G})$ Dorsal views; anterior to the left. $(\mathbf{H})$ Anterior view; dorsal to the left.

One of the most striking aspects of O. alcalica development was the emergence of an extensive vascular system which began in patches on the yolk and subsequently branched and formed a network of vessels across the yolk between 3 and $4 \mathrm{dpf}$ (Figure 1G,H). In the closely related freshwater Nile tilapia (O. niloticus), the earliest heartbeat and blood circulation were reported at $40-42 \mathrm{hpf}$, and yolk vascularisation was also observed at $4 \mathrm{dpf}[49,54]$. When cultured at about the same temperature 
used in these previous studies $\left(28-30^{\circ} \mathrm{C}\right)$, we found and recorded heart contractions at $66 \mathrm{hpf}, 3 \mathrm{dpf}$, $4 \mathrm{dpf}$, and $5 \mathrm{dpf}$, as shown in movies in the Supplementary Materials. The early vascularisation seen in these cichlids is very unlike that of Danio rerio and shows more similarity to vascularisation seen in aminotes such as chick embryos. To investigate this further, the genes for the conserved cardiac transcription factors, gata4, $t b x 5$, and $m e f 2 c$, were cloned from extracted RNA and used for in situ hybridisation studies in O. alcalica. The expression of these genes was previously described in zebrafish [55-57]; nevertheless, they are included here for comparison. To do this, gat $a 4$, tbx5, and mef $2 c$ were cloned from zebrafish and analysed by in situ hybridisation, as presented in Figures S1-S3 (Supplementary Materials).

\section{2. gata4 is Expressed in Cardiac and Haematopoietic Regions of O. alcalica Embryos}

To confirm that the cDNA isolated from O. alcalica was indeed gata4, a phylogenetic analysis was undertaken and revealed high conservation of our sequence with known GATA4 proteins (Figure 2A). In situ hybridisation analysis of embryos fixed at $2 \mathrm{dpf}$ showed that the expression of Oa gata4 in the linear heart tube was localised at the anterior left side of the embryo (Figure 2B,C), consistent with our observations of the early pharyngula stage, where the contracting linear heart tube forms (Figure 1F, Supplementary Movie A). The gata4 expression in the heart tube was more restricted by $3 \mathrm{dpf}$ (Figure 2E,F), and, by $7 \mathrm{dpf}$, gata 4 transcripts were still detected in a limited region of the heart. The gata4 in situ hybridisation of zebrafish at $1 \mathrm{dpf}$ identified gata4-expressing cardiomyocytes in the anterior lateral plate mesoderm (Figure S1A,B), and, by $2 \mathrm{dpf}$ and $3 \mathrm{dpf}$, gata 4 transcripts were expressed in the anterior midline (Figure S1C-F). Other regions of gata4 expression were identified at the posterior of the embryo in the haematopoietic region (Figure 2B,C).

Later in development, at $3 \mathrm{dpf}$ and $7 \mathrm{dpf}$, gata4 transcripts localised to numerous puncta across the yolk (Figure 2D-H). The embryos in Figure 2F-H were bleached to remove pigmentation from melanocytes, allowing better visualisation of these puncta. The gata 4 expression on the yolk, overlapping with the extensive vasculature, was first distinguishable at $3 \mathrm{dpf}$ (Figure 1F). These extraembryonic gata4-expressing puncta were likely blood islands (Figure 2D-H), a feature of haematopoiesis that is absent in zebrafish, but present during amniote development.

As $O$. alcalica are direct-developers, they are more dependent on the yolk as an energy source than indirect-developers that have a free-feeding larval stage such as zebrafish. The development of this early vasculature from blood islands likely provides a vital, early energy supply in $O$. alcalica embryos. Interestingly, it is not GATA4, but GATA1 and GATA2 that are expressed in the blood islands of chicks and mice $[59,60]$.

\section{3. tbx5 is Expressed in the Developing Pectoral Fin, Eyes, and Heart of O. alcalica}

The expression of $O a$ tbx 5 was found in the heart, limb, and eye by in situ hybridisation, consistent with its expression in other vertebrate embryos. Phylogenetic analysis of Tbx5 protein in multiple vertebrates confirmed the identity of the $t b x 5 \mathrm{cDNA}$ isolated from O. alcalica (Figure 3A). At $2 \mathrm{dpf}$ and $3 \mathrm{dpf}, \mathrm{Oa}$ tbx 5 transcripts were detected and localised specifically to the dorsal region of the eyes (Figure 3B,C). This expression in the eye was easily visualised prior to pigmentation of the retina in O. alcalica; however, by $7 \mathrm{dpf}, \mathrm{Oa} t b \times 5$ expression in the eye was not visible in the retinal pigment epithelium (RPE) due to the black pigmentation (Figure 3F,G). This expression of $O a$ tb $x 5$ in the dorsal retina is conserved in vertebrates [61-63], and, in zebrafish, $t b x 5 b$ was expressed in the dorsal retina from 1-3 dpf (Figure S2).

At $3 \mathrm{dpf}$, there was transient expression of $O a$ tbx 5 in the heart (Figure 3D), as also seen in zebrafish (Figure S2). The expression of Oa tbx5 in O. alcalica hearts at $3 \mathrm{dpf}$, during the linear heart tube stage, is consistent with the known role of Tbx5 in regulating cardiac looping and jogging in zebrafish. At $3 \mathrm{dpf}, \mathrm{Oa}$ tbx 5 transcripts localised to the O. alcalica pectoral limb bud (LB) (Figure 3D,E). Oa tbx5 was still expressed in the LB at $7 \mathrm{dpf}$ (Figure 3F, G). Similarly, in zebrafish, $t b x 5 b$ was expressed in the LB from 1-3 dpf (Figure S2). 


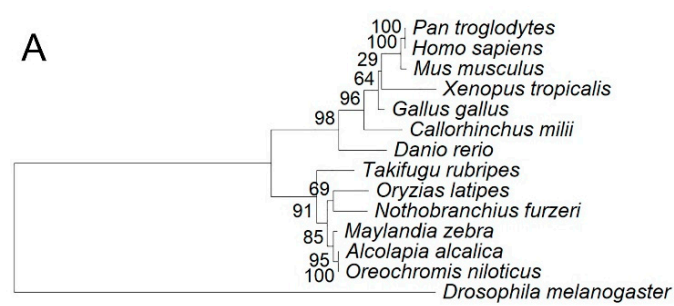

0.50
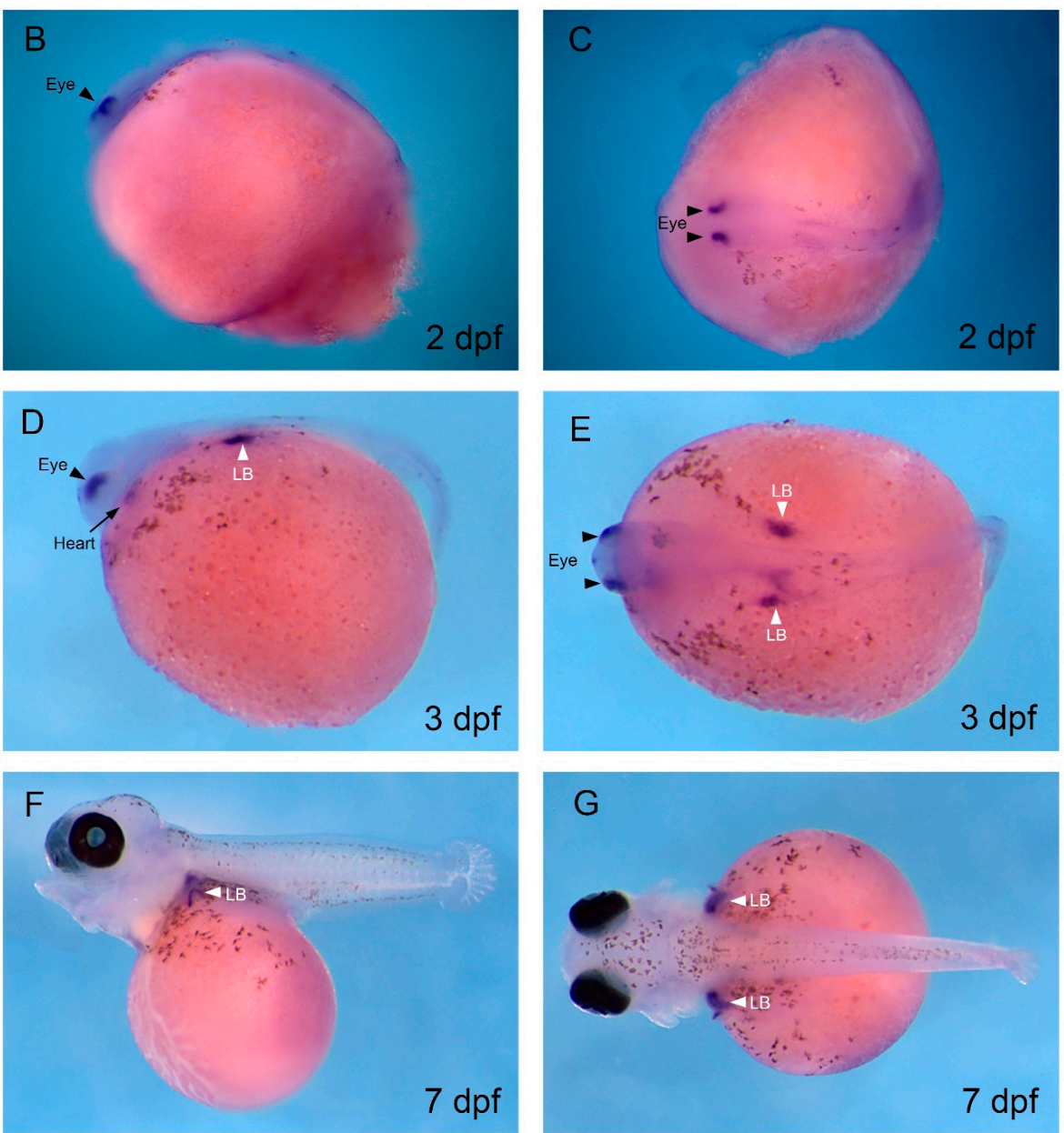

Figure 3. $t b x 5$ expression in O. alcalica dorsal retina, heart, and pectoral limb buds. (A) Phylogenetic analysis of Tbx5. The evolutionary history was inferred using the maximum likelihood method and Jones with frequency model [64]. (B-G) In situ hybridisation of $O$. alcalica $t b x 5$ at 2 days post fertilisation (dpf) (B,C), $3 \mathrm{dpf}(\mathbf{D}, \mathbf{E})$, and $7 \mathrm{dpf}(\mathbf{F}, \mathbf{G})$. At $2 \mathrm{dpf}, t b x 5$ was expressed in the dorsal region of the eye $(\mathbf{B}, \mathbf{C})$. At $3 \mathrm{dpf}, t b x 5$ was expressed in the eye, heart, and limb bud (LB) (D,E). At $7 \mathrm{dpf}$, $t b x 5$ was expressed in the LB $(\mathbf{F}, \mathrm{G})$. Black arrows denote the heart, black arrowheads mark the eyes, and white arrowheads denote the limb buds (LB). (B,D,F) Lateral views; anterior to the left. (C,E,G) Dorsal views; anterior to the left.

\section{4. mef2c is Expressed in Developing Muscle in O. alcalica}

The expression of the highly conserved cardiomyogenic regulator, $m e f 2 c$, was assessed in O. alcalica by in situ hybridisation. In Drosophila, D-mef2 is essential for the formation of cardiac muscle, and loss of $D$-mef2 results in failure of cardiomyocyte differentiation $[45,65]$. In zebrafish, Mef2c is also required for cardiac development; combinatorial loss-of-function of mef2ca and $m e f 2 c b$ causes developmental arrest of cardiomyocytes. These mef $2 c$ paralogues control the expression of myocardial sarcomeric 
genes [66]. Phylogenetic analysis of Mef2c protein in multiple vertebrates confirmed the identity of the Oa mef2c cDNA isolated from O. alcalica (Figure 4A), and it was distinct from the highly related Mef2d sequences (Supplementary Materials). Consistent with previous studies, Dr mef2ca transcripts were detected by in situ hybridisation in early cardiac regions in zebrafish (Figure S3); however, we found no expression of $\mathrm{Oa}$ mef2c in cardiac regions of $\mathrm{O}$. alcalica. The expression shown in Figure 4B-E is similar to that described in Xenopus laevis [67], and we expect that the stages we analysed were too late to detect $\mathrm{Oa}$ mef $2 c$ in the heart because it is an early regulator of cardiac differentiation. Nonetheless, our expression analysis provides insight into the process of myogenesis in O. alcalica; at $2 \mathrm{dpf}$ and $3 \mathrm{dpf}$, Oa mef $2 c$ was robustly expressed in the somites (Figure 4B-E), the embryonic source of all skeletal muscle in the vertebrate body [68]. This expression is conserved in zebrafish where mef2ca transcripts were also detected in somites from 1-3 dpf (Figure S3).
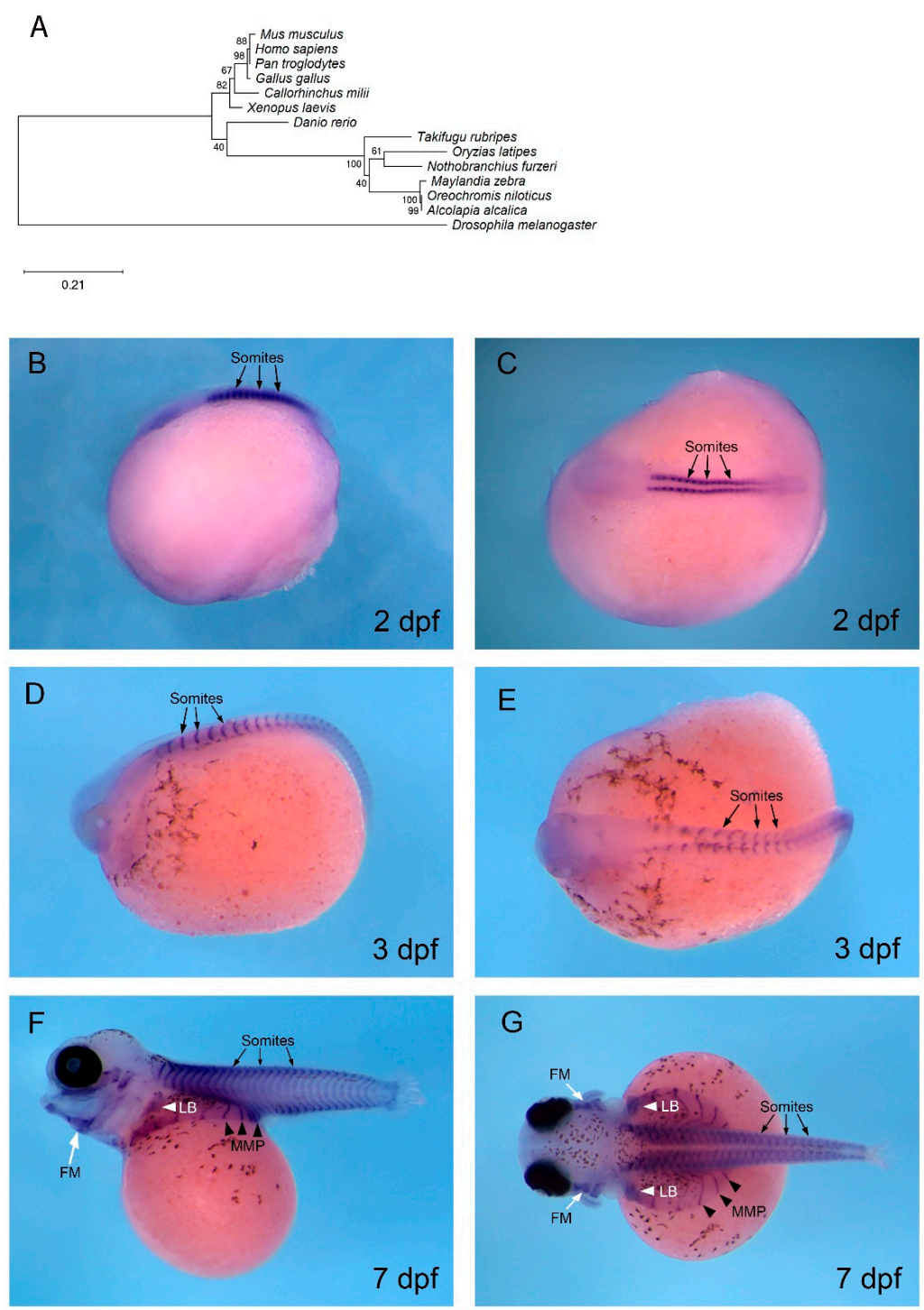

Figure 4. $m e f 2 c$ is expressed in developing muscle in O. alcalica. (A) Phylogenetic analysis of Mef2c. The evolutionary history was inferred by the maximum likelihood method and Jones with frequency model [64]. (B-G) In situ hybridisation of O. alcalica mef2c at 2 days post fertilisation (dpf) (B,C), $3 \mathrm{dpf}$ $(\mathbf{D}, \mathbf{E})$, and $7 \mathrm{dpf}(\mathbf{F}, \mathbf{G})$. At $2 \mathrm{dpf}$ and $3 \mathrm{dpf}, m e f 2 c$ was expressed in the somites (B-E). At $7 \mathrm{dpf}, m e f 2 c$ was expressed in somites, limb buds (LB), migrating muscle precursors (MMP), and facial muscle (FM). Black arrows denote the somites, black arrowheads mark migrating muscle precursors (MMP), white arrows denote facial muscle (FM), and white arrowheads mark limb buds (LB). (B,D,F) Lateral views; anterior to the left. $(\mathbf{C}, \mathbf{E}, \mathbf{G})$ Dorsal views; anterior to the left. 
At $7 \mathrm{dpf}, \mathrm{Oa}$ mef $2 \mathrm{c}$ continued to be expressed in the distinctive chevron structure of the somites and in hypaxial muscle. These $O a$ mef2c-expressing streams of migratory muscle precursors (MMPs) migrated to form the muscles of the ventral body wall (arrowheads in Figure 4F,G). In O. alcalica, Oa mef2c expression revealed that the MMPs spread out as direct extensions of anterior somites that extended ventrally across the yolk; these extensions were not seen in zebrafish embryos.

\section{Discussion}

We report here the expression of three evolutionarily conserved regulators of cardiogenesis in the context of a direct-developing extremophile fish, Oreochromis (Alcolapia) alcalica. We include a developmental stage series and a set of videos to illustrate the onset of heart development and contraction.

\section{1. gata4}

Bilateral cardiomyocytes in the anterior lateral plate mesoderm can be identified through expression of gata4/5/6 [69,70]. GATA4, in particular, is a potent driver of cardiac myogenesis; ectopically expressed gata4 induces pluripotent Xenopus animal cap organoids to form contracting cardiomyocyte tissue [71]. Furthermore, human congenital heart defects are linked to mutations in GATA4, including valve and septal defects [72,73]. Morpholino oligonucleotide (MO) knockdown of gata4/5/6 in Xenopus and zebrafish embryos attests to their roles in cardiac myogenesis. Xenopus morphants of individual GATA factors display cardia bifida, whereas knockdown of all three GATA factors eliminated expression of markers of cardiac differentiation [74]. In zebrafish, however, MO knockdown of gata5 and gata6 resulted in cardia bifida and substantial reduction in expression of contractile protein genes, whereas gata4 morphant cardiomyocytes migrated to the midline normally [74]. The difference in phenotype severity of gata5 morphants in Xenopus and zebrafish suggests a change in the activity of these GATA factors during evolution [75].

Our finding that Oa gata4 is expressed in blood islands, the bipotential precursors of both vascular endothelia and blood cells, is interesting. In zebrafish and mammals, haematopoiesis occurs in shifting anatomical regions of the developing embryo [76]. In zebrafish, haematopoietic stem cells (HSCs) arise from the hemogenic endothelium lining the ventral wall of the dorsal aorta (VDA) [77]. HSCs originating from the VDA seed three haematopoietic organs: the caudal haematopoietic tissue (CHT), the thymus, and the kidney, the adult site of haematopoiesis in zebrafish [78]. In mammals, the VDA is functionally equivalent to the aorta-gonad-mesonephros (AGM) [79,80]. Mammalian HSCs emerge from the AGM, and transiently expand in the foetal liver before being maintained in the bone marrow, the adult site of haematopoiesis [81-83]. The mammalian foetal liver is equivalent to the zebrafish CHT, a vascularised region in the tail [84]. It was shown that primary cell lines generated from the zebrafish $\mathrm{CHT}$ at $3 \mathrm{dpf}$ support HSC proliferation and differentiation [85]. The posterior region expressing Oa gata4 in O. alcalica, labelled as the haematopoietic region (Figure 2B,C), may be similar to the CHT in zebrafish.

Blood islands in mice and chick form as clusters of mesodermal cells in the yolk sac that accumulate haemoglobin and are surrounded by outer endodermal cells that flatten and later form the endothelium of blood vessels [86]. The mesodermal and endodermal lineages that form the blood islands derive from common precursors known as hemangioblasts [87]. Zebrafish do not form yolk sac blood islands during embryogenesis. However, in some fish, such as killifish (Fundulus spp.), angelfish (Pterophylum scalare), and chondrichthyans, blood development predominantly occurs in the yolk sac [88]. This suggests that there is diversity in the location of embryonic blood development in teleosts.

The sites of haematopoiesis and vasculogenesis in O. alcalica embryos are more aligned with blood development in amniotes than with zebrafish. In vertebrates, the conserved GATA factors are divided into two subfamilies; gata1/2/3 are expressed in developing blood cells, and gata4/5/6 are expressed in mesodermal and endodermal tissues such as heart, liver, pancreas, and gut [89]. In the murine yolk sac, GATA1 and GATA2 transcripts were detected in blood islands by in situ hybridisation. Furthermore, 
GATA1- and GATA2-null mouse embryos are deficient in erythroid cells [60,90-92]. This suggests that, in mice, GATA1 and GATA2 are crucial for haematopoietic development in the yolk sac. Our novel finding that $\mathrm{Oa}$ gata4 transcripts localise to blood islands of $O$. alcalica embryos raises the possibility of the neofunctionalisation of Alcolapia GATA factors. Therefore, it would be valuable to undertake further research with the aim of characterising the expression and function of other GATA factors in O. alcalica development.

\section{2. $t b x 5$}

Due to its clinical relevance, $t b x 5$ loss-of-function vertebrate models have been developed [93,94]. Septation is the process whereby the looped heart tube transitions into a multi-chambered heart; this occurs via the addition of cardiomyocytes that contribute to the atrium and the inflow tract [95]. Conditional knockout mice, whereby Tbx 5 is haplo-insufficient only in these cardiomyocytes, showed that $t b x 5$ expression is required for the proliferation of atrial septum progenitors [96]. Furthermore, tissue-specific deletion of $t b x 5$ in ventricular cardiomyocytes of mice resulted in cardiac contraction dysfunction, which reflects HOS patient symptoms [97]. A tbx5 mutant strain has been developed in zebrafish, known as the heartstrings mutant. In heartstrings mutants, the heart tube at $1 \mathrm{dpf}$ is indistinguishable from wild type. Similar to HOS patients and the conditional knockout mice, they display a reduction in rate of contraction. Heartstrings hearts do not undergo looping but remain as linear heart tubes. By 3-4 dpf, they stretch to a string-like morphology [94]. Furthermore, double MO knockdowns of both $t b x 5$ paralogues display defects in cardiac jogging and looping; linear heart tubes remain at the midline or jog to the right, and looping is either abolished or reversed [98].

The role of $t b x 5$ in eye development has been examined in chick embryos by misexpressing this gene in the ventral retina. This resulted in upregulation of dorsal markers and downregulation of ventral markers, as well as altered projections of retinal ganglion cells [99]. In zebrafish, MO knockdown of both $t b x 5$ paralogues, $t b x 5 a$ and $t b x 5 b$, significantly reduces the expression domains of dorsal markers in the eye [98]. Furthermore, transcriptomic analysis revealed that 54 genes were differentially expressed in the eye in these double-morphant embryos [100]. This suggests that $t b x 5$ is critical in dorsal-ventral patterning of the developing retina in vertebrates, which is consistent with this specific expression observed in O. alcalica.

Fish pectoral fins are homologous to tetrapod forelimbs, and genetic loss of function of $t b x 5$ in mice results in absence of forelimbs [101-103]. Similarly, in zebrafish, tbx5b morphants develop smaller limbs than controls [98]. The LB is established at a specific antero-posterior position of the lateral plate mesoderm. Limb mesenchyme precursors protrude from the trunk to form the LB. At the distal tip of the LB is the apical ectodermal ridge which controls LB growth [104]. tbx5 is the earliest gene to be expressed in the presumptive pectoral fin mesenchyme, and the regulation of $t b x 5$ expression in vertebrates has been crucial to understanding the evolutionary origin of paired appendages. In situ hybridisation analysis of $t b x 5$ during development of the vertebrate sea lamprey (Petromyzon marinus), which does not have paired appendages, found $t b x 5$ expression to be exclusive to the heart field. It was, therefore, hypothesised that $t b x 5$ expression in the lateral plate mesoderm posterior to the heart is associated with the evolution of pectoral fins [105]. A study aimed at identifying a limb-specific enhancer of $t b x 5$ identified a potential cis-regulatory element downstream from $t b x 5$ conserved in vertebrates, known as cns12sh. Injection of tbx5 alongside cns12sh into heartstrings embryos, which do not develop pectoral limbs, rescued LB development [105]. However, CRISPR/Cas9 knockout of endogenous cns12sh regulatory elements in mice and zebrafish exhibited normal tbx 5 expression and LB initiation, suggesting there may be other DNA elements that share redundant function or that cns12sh is a pseudo-enhancer that was once required for LB activation but was lost during evolution [106]. Therefore, noncoding DNA elements that regulate $t b x 5$ expression in the vertebrate LB remain elusive. Further limb enhancers could be identified by comparative analyses of the genomic landscape of vertebrate $t b x 5$ including $O$. alcalica, which shares this specific expression in the LB. 


\section{3. $m e f 2 c$}

An essential role for Mef2c in heart development was revealed when Mef2c-null mice were found to be embryonic lethal due to abnormalities in inflow tract and outflow tract formation, and insufficient cardiac looping results in complete absence of the right ventricle [107-109]. More recently, this phenotype was recapitulated in mice with cardiomyocyte-specific Mef2c deletions [110]. Similarly, zebrafish Mef2c is crucial in early heart and skeletal muscle development $[66,111,112]$. Two mef2c paralogues exist in zebrafish: $m e f 2 c a$ and $m e f 2 c b$ [113]. Mef2cb is expressed in cardiomyocytes, and MO knockdown of $m e f 2 c b$ eliminates cardiomyocytes in the outflow tract, reminiscent of Mef2c-null mice [112]. Combinatorial loss-of-function analysis of both paralogues revealed an essential role of $m e f 2 c a$ and $b$ in controlling the expression of myocardial sarcomeric genes in cardiomyocytes [66].

Although we found no cardiac expression of $O$. alcalica mef $2 c$ at the stages we investigated (Figure 4B-G), we conclude that this is because we did not look early enough. In a study of the Mef2 family in Atlantic cod (Gadus morhua), mef2c was robustly expressed at the cardiac ring stage, during cardiac ring extension at the arterial and venous poles, and after completion of heart formation [114]. Although invertebrates only have a single mef2 gene, amniotes have four genes (Mef2a-d) [115]. The teleost-specific gene duplication has led to six mef2 genes in zebrafish that undergo extensive alternative splicing $[66,116]$.

We did find extensive expression of $O a$ mef $2 c$ in the skeletal muscle cell lineage (in the somites, limb buds, facial muscle, and MMPs) which is also seen in Xenopus [67] and zebrafish ([66] (Figure S3C-F). Cells become committed to the myogenic lineage via the cooperation of myogenic regulatory factors (MRFs) Myod, Myf5, Myogenin, and Mrf4, [117] and members of the MEF2 family. mef2 genes are activated by MRFs and expressed during the terminal differentiation of muscle cells [44,118]. It has been shown that mef2 genes are required in myogenesis in zebrafish, as mef2 knockdown by MOs causes downregulation of messenger RNAs (mRNAs) encoding thick filament proteins (myosins), resulting in disrupted sarcomere assembly [111].

Two distinct mechanisms of MMP migration have been described for the body wall and appendage musculature. There is the primitive mechanism of direct epithelial somitic extension, whereby differentiated muscle of the somite extends directly to provide musculature of the body wall. Alternatively, there is a mechanism of long-range migration, whereby MMPs delaminate from somites after undertaking epithelial-to-mesenchymal transition and undergo long-range migration [119]. In zebrafish fin development, some hypaxial muscle precursors are specified in the somites and undergo long-range migration. This was established by assessing expression of $l b x 1$, a gene that specifically labels limb muscle precursors [120,121]. In contrast, the body wall musculature of amniotes and the development of chondrichthyan fin muscles are formed via direct extension from the somites [121-123]. Therefore, this expression analysis of mef $2 c$ in O. alcalica shows body wall musculature extending from somites, consistent with findings in amniotes [122]. In contrast, it appears that $\mathrm{Oa}$ mef2c-expressing myocytes in the LB are separated from somites, indicating that long-range migration is the likely mechanism via which muscle precursors move to the LB, similar to terrestrial vertebrates. To conclusively determine the mechanism of hypaxial migration, further expression analyses of genes regulating MMP migration, such as $l b x 1[120,121]$, should be undertaken.

\section{Perspectives}

Understanding acquired adaptations of $O$. alcalica that allow it to thrive in extreme conditions could be useful when projecting resilience of other freshwater vertebrates living in ecosystems affected by climate change. The developmental stage series presented here reveals $O$. alcalica as a direct-developing teleost and, together with the described methods for undertaking expression analyses, this forms the basis of comparative developmental work with other cichlids. A notable limitation of this study was the difficulty in analysing O. alcalica blastula-gastrula stages of development, and, for future studies, it would be valuable to develop a method of observing gene expression in these early embryos. 
Overall, our findings show that $O$. alcalica shares the highly conserved molecular regulation of the vertebrate body plan. gata 4 and $t b x 5$ are expressed in the $O$. alcalica embryonic heart, consistent with these genes having a conserved role in cardiac development in this species. Surprisingly, we also found $\mathrm{Oa}$ gata4 localised to haematopoietic regions of the developing embryo, including yolk sac blood islands, which are characteristic of amniote blood development. The prominence of Oa gata4 expression in haematopoietic regions sets it apart from other vertebrates; thus, it would be informative to characterise the phylogeny and expression of other members of the GATA family in O. alcalica.

Supplementary Materials: The following are available online at http:/www.mdpi.com/2221-3759/8/4/22/s1: Figure S1. Expression of cardiac regulator gata4 in zebrafish; Figure S2. Expression of cardiac regulator $t b x 5 b$ in zebrafish; Figure S3. Expression of cardiac regulator mef2ca in zebrafish; Movies: Contracting heart during O. alcalica development.

Author Contributions: Data curation, G.S. and L.J.W.; investigation, A.G.P.F. and A.S.; methodology, L.J.W.; supervision, K.K.D. and M.E.P.; writing-original draft, G.S.; writing-review and editing, A.G.P.F. and J.J.D. All authors have read and agreed to the published version of the manuscript.

Funding: L.J.W. was supported by a BBSRC PhD studentship (BB/M011151/1) which funded the work.

Acknowledgments: G.S. carried out this work as part of an undergraduate project at the University of York. The fish were collected from Lake Natron by L.J.W., J.J.D., A.G.P.F. and A.S. with the Tanzania Fishery Research Institute (TAFIRI) (COSTECH permit no. 2017-259- NA-2011-182).

Conflicts of Interest: The authors declare no conflict of interest.

\section{References}

1. Evans, D.H.; Piermarini, P.M.; Choe, K.P. The Multifunctional Fish Gill: Dominant Site of Gas Exchange, Osmoregulation, Acid-Base Regulation, and Excretion of Nitrogenous Waste. Physiol. Rev. 2005, 85, 97-177. [CrossRef]

2. Hwang, P.-P.; Lee, T.-H.; Lin, L.-Y. Ion regulation in fish gills: Recent progress in the cellular and molecular mechanisms. Am. J. Physiol. Integr. Comp. Physiol. 2011, 301, R28-R47. [CrossRef]

3. Helfman, G.; Collette, B.B.; Facey, D.E.; Bowen, B.W. The Diversity of Fishes: Biology, Evolution, and Ecology; John Wiley \& Sons: Hoboken, NJ, USA, 2009.

4. Wang, Y.; Guo, B. Adaption to extreme environments: A perspective from fish genomics. Rev. Fish. Biol. Fish. 2019, 29, 735-747. [CrossRef]

5. Riesch, R.; Tobler, M.; Plath, M. Extremophile Fishes: Ecology, Evolution, and Physiology of Teleosts in Extreme Environments; Springer: New York, NY, USA, 2015.

6. Garbarino, V.R.; Orr, M.E.; Rodriguez, K.A.; Buffenstein, R. Mechanisms of oxidative stress resistance in the brain: Lessons learned from hypoxia tolerant extremophilic vertebrates. Arch. Biochem. Biophys. 2015, 576, 8-16. [CrossRef] [PubMed]

7. Irwin, J.A. Extremophiles and their application to veterinary medicine. Environ. Technol. 2010, 31, 857-869. [CrossRef] [PubMed]

8. Jorge, C.D.; Borges, N.; Bagyan, I.; Bilstein, A.; Santos, H. Potential applications of stress solutes from extremophiles in protein folding diseases and healthcare. Extremophiles 2016, 20, 251-259. [CrossRef]

9. Jeffery, W.R. Chapter 8 Evolution and Development in the Cavefish Astyanax. Curr. Top. Dev. Biol. 2009, 86, 191-221. [CrossRef]

10. Kimmel, C.B.; Ballard, W.W.; Kimmel, S.R.; Ullmann, B.; Schilling, T.F. Stages of embryonic development of the zebrafish. Dev. Dyn. 1995, 203, 253-310. [CrossRef]

11. Iwamatsu, T. Stages of normal development in the medaka Oryzias latipes. Mech. Dev. 2004, 121, 605-618. [CrossRef]

12. Froese, R.; Pauly, D.; FishBase. World Wide Web electronic publication. Available online: https://www. scienceopen.com/document?vid=dc419213-0ca3-48cc-901c-2934ecf4441e (accessed on 2 January 2014).

13. Crawford, D.L. Functional genomics does not have to be limited to a few select organisms. Genome Biol. 2001, 2, 1001.

14. Kocher, T.D. Adaptive evolution and explosive speciation: The cichlid fish model. Nat. Rev. Genet. 2004, 5, 288-298. [CrossRef] [PubMed]

15. Salzburger, W.; Meyer, A. The species flocks of East African cichlid fishes: Recent advances in molecular phylogenetics and population genetics. Naturwissenschaften 2004, 91, 277-290. [CrossRef] [PubMed] 
16. McGee, M.D.; Faircloth, B.C.; Borstein, S.R.; Zheng, J.; Hulsey, C.D.; Wainwright, P.C.; Alfaro, M.E. Replicated divergence in cichlid radiations mirrors a major vertebrate innovation. Proc. R. Soc. 2016, 283, 20151413. [CrossRef]

17. Ford, A.G.P.; Bullen, T.R.; Pang, L.; Genner, M.J.; Bills, R.; Flouri, T.; Ngatunga, B.P.; Ruber, L.; Schliewen, U.K.; Seehausen, O.; et al. Molecular phylogeny of Oreochromis (Cichlidae: Oreochromini) reveals mito-nuclear discordance and multiple colonisation of adverse aquatic environments. Mol. Phylogenetics Evol. 2019, 136, 215-226. [CrossRef]

18. Roberts, N.; Taieb, M.; Barker, P.; Damnati, B.; Icole, M.; Williamson, D. Timing of the Younger Dryas event in East Africa from lake-level changes. Nature 1993, 366, 146-148. [CrossRef]

19. Tichy, H.; Seegers, L. The Oreochromis alcalicus flock (Teleostei Cichlidae) from lakes Natron and Magadi, Tanzania and Kenya: A model for the evolution of new species flocks in historical times. Ichthyol. Explor. Freshw. 1999, 10, 147-174.

20. Ford, A.G.P.; Dasmahapatra, K.K.; Rüber, L.; Gharbi, K.; Cezard, T.; Day, J.J. High levels of interspecific gene flow in an endemic cichlid fish adaptive radiation from an extreme lake environment. Mol. Ecol. 2015, 24, 3421-3440. [CrossRef]

21. Clarisse, L.; Van Damme, M.; Gardner, W.; Coheur, P.-F.; Clerbaux, C.; Whitburn, S.; Hadji-Lazaro, J.; Hurtmans, D. Atmospheric ammonia $\left(\mathrm{NH}_{3}\right)$ emanations from Lake Natron's saline mudflats. Sci. Rep. 2019, 9, 4441. [CrossRef]

22. Randall, D.J.; Wood, C.M.; Perry, S.F.; Bergman, H.; Maloiy, G.M.O.; Mommsen, T.P.; Wright, P.A. Urea excretion as a strategy for survival in a fish living in a very alkaline environment. Nature 1989, 337, 165-166. [CrossRef]

23. Narahara, A.; Bergman, H.L.; Laurent, P.; Maina, J.N.; Walsh, P.J.; Wood, C.M. Respiratory physiology of the Lake Magadi Tilapia (Oreochromis alcalicus grahami), a fish adapted to a hot, alkaline, and frequently hypoxic environment. Physiol. Zool. 1996, 69, 1114-1136. [CrossRef]

24. Bergman, A.N.; Laurent, P.; Otiang'a-Owiti, G.; Bergman, H.L.; Walsh, P.J.; Wilson, P.; Wood, C.M. Physiological adaptations of the gut in the Lake Magadi tilapia, Alcolapia grahami, an alkaline- and saline-adapted teleost fish. Comp. Biochem. Physiol. Part. A Mol. Integr. Physiol. 2003, 136, 701-715. [CrossRef]

25. Kavembe, G.D.; Franchini, P.; Irisarri, I.; Machado-Schiaffino, G.; Meyer, A. Genomics of Adaptation to Multiple Concurrent Stresses: Insights from Comparative Transcriptomics of a Cichlid Fish from One of Earth's Most Extreme Environments, the Hypersaline Soda Lake Magadi in Kenya, East Africa. J. Mol. Evol. 2015, 81, 90-109. [CrossRef] [PubMed]

26. Wood, C.M.; Brix, K.V.; De Boeck, G.; Bergman, H.L.; Bianchini, A.; Bianchini, L.F.; Maina, J.N.; Johannsson, O.E.; Kavembe, G.D.; Papah, M.B.; et al. Mammalian metabolic rates in the hottest fish on earth. Sci. Rep. 2016, 6, 26990. [CrossRef] [PubMed]

27. White, L.J.; Sutton, G.; Shechonge, A.; Day, J.J.; Dasmahapatra, K.K.; Pownall, M.E. Adaptation of the carbamoyl-phosphate synthetase (CPS) enzyme in an extremophile fish. R. Soc. Open Sci. 2020, in press.

28. Bishopric, N.H. Evolution of the Heart from Bacteria to Man. Ann. New York Acad. Sci. 2005, 1047, 13-29. [CrossRef]

29. Solc, D. The heart and heart conducting system in the kingdom of animals: A comparative approach to its evolution. Exp. Clin. Cardiol. 2007, 12, 113-118.

30. Meijler, F.L.; Meijler, T.D. Archetype, adaptation and the mammalian heart. Neth. Hear. J. 2011, 19, 142-148. [CrossRef]

31. Asnani, A.; Peterson, R.T. The zebrafish as a tool to identify novel therapies for human cardiovascular disease. Dis. Model. Mech. 2014, 7, 763-767. [CrossRef]

32. Stainier, D.Y.; Lee, R.K.; Fishman, M.C. Cardiovascular development in zebrafish. I. Myocardial fate map and heart tube formation. Development 1993, 119, 31-40.

33. Keegan, B.R.; Meyer, D.; Yelon, D. Organization of cardiac chamber progenitors in the zebrafish blastula. Development 2004, 131, 3081-3091. [CrossRef]

34. Yelon, D.; Horne, S.A.; Stainier, D.Y.R. Restricted expression of cardiac myosin genes reveals regulated aspects of heart tube assembly in zebrafish. Dev. Biol. 1999, 214, 23-37. [CrossRef] [PubMed]

35. Rohr, S.; Otten, C.; Abdelilah-Seyfried, S. Asymmetric involution of the myocardial field drives heart tube formation in zebrafish. Circ. Res. 2008, 102, 12-19. [CrossRef] 
36. Chen, J.N.; van Eeden, F.J.; Warren, K.S.; Chin, A.; Nusslein-Volhard, C.; Haffter, P.; Fishman, M.C. Left-right pattern of cardiac BMP4 may drive asymmetry of the heart in zebrafish. Development 1997, 124, 4373-4382.

37. Beis, D.; Bartman, T.; Jin, S.-W.; Scott, I.C.; D'Amico, L.A.; Ober, E.A.; Verkade, H.; Frantsve, J.; Field, H.A.; Wehman, A.; et al. Genetic and cellular analyses of zebrafish atrioventricular cushion and valve development. Development 2005, 132, 4193-4204. [CrossRef]

38. Fossett, N.; Schulz, R.A. Functional conservation of hematopoietic factors in Drosophila and vertebrates. Differentiation 2001, 69, 83-90. [CrossRef] [PubMed]

39. Nemer, G.M.; Nemer, M. Regulation of heart development and function through combinatorial interactions of transcription factors. Ann. Med. 2001, 33, 604-610. [CrossRef] [PubMed]

40. Holt, M.; Oram, S. Familial heart disease with skeletal malformations. Br. Heart J. 1960, 22, 236-242. [CrossRef]

41. Basson, C.T.; Cowley, G.S.; Solomon, S.D.; Weissman, B.; Poznanski, A.K.; Traill, T.A.; Seidman, J.G.; Seidman, C.E. The Clinical and Genetic Spectrum of the Holt-Oram Syndrome (Heart-Hand Syndrome). N. Engl. J. Med. 1994, 330, 885-891. [CrossRef]

42. Newbury-Ecob, R.A.; Leanage, R.; Raeburn, J.A.; Young, I.D. Holt-Oram syndrome: A clinical genetic study. J. Med. Genet. 1996, 33, 300-307. [CrossRef]

43. Basson, C.T.; Bachinsky, D.R.; Lin, R.C.; Levi, T.; Elkins, J.A.; Soults, J.; Grayzel, D.; Kroumpouzou, E.; Traill, T.A.; Leblanc-Straceski, J.; et al. Mutations in human cause limb and cardiac malformation in Holt-Oram syndrome. Nat. Genet. 1997, 15, 30-35. [CrossRef]

44. Black, B.L.; Olson, E.N. Transcriptional control of muscle development by myocyte enhancer factor-2 (MEF2) proteins. Annu. Rev. Cell Dev. Bio. 1998, 14, 167-196. [CrossRef] [PubMed]

45. Lilly, B.; Zhao, B.; Ranganayakulu, G.; Paterson, B.M.; Schulz, R.A.; Olson, E.N. Requirement of MADS domain transcription factor D-MEF2 for muscle formation in Drosophila. Science 1995, 267, 688-693. [CrossRef] [PubMed]

46. Edmondson, D.G.; Lyons, G.E.; Martin, J.F.; Olson, E.N. Mef2 gene expression marks the cardiac and skeletal muscle lineages during mouse embryogenesis. Development 1994, 120, 1251-1263. [PubMed]

47. Ford, A.G.P.; Rüber, L.; Newton, J.; Dasmahapatra, K.K.; Balarin, J.D.; Bruun, K.; Day, J.J. Niche divergence facilitated by fine-scale ecological partitioning in a recent cichlid fish adaptive radiation. Evolution 2016, 70, 2718-2735. [CrossRef] [PubMed]

48. Kumar, S.; Stecher, G.; Li, M.; Knyaz, C.; Tamura, K. MEGA X: Molecular Evolutionary Genetics Analysis across Computing Platforms. Mol. Biol. Evol. 2018, 35, 1547-1549. [CrossRef]

49. Fujimura, K.; Okada, N. Development of the embryo, larva and early juvenile of Nile tilapia Oreochromis niloticus (Pisces: Cichlidae). Developmental staging system. Dev. Growth. Differ. 2007, 49, 301-324. [CrossRef]

50. De Jong, I.M.L.; Witte, F.; Richardson, M.K. Developmental stages until hatching of the Lake Victoria cichlid Haplochromis piceatus (Teleostei: Cichlidae). J. Morphol. 2009, 270, 519-535. [CrossRef]

51. Woltering, J.M.; Holzem, M.; Schneider, R.F.; Nanos, V.; Meyer, A. The skeletal ontogeny of Astatotilapia burtoni-a direct-developing model system for the evolution and development of the teleost body plan. BMC Dev. Biol. 2018, 18. [CrossRef]

52. Flegler-Balon, C. Direct and Indirect Development in Fishes-Examples of Alternative Life-History Styles; Springer Science and Business Media LLC: Dordrecht, The Netherland, 1989; Volume 6, pp. 71-100.

53. Balon, E.K. Alternative Ways to Become a Juvenile or a Definitive Phenotype (and on Some Persisting Linguistic Offenses). Environ. Boil. Fishes 1999, 56, 17-38. [CrossRef]

54. Le Pabic, P.; Stellwag, E.J.; Scemama, J.-L. Embryonic Development and Skeletogenesis of the Pharyngeal Jaw Apparatus in the Cichlid Nile Tilapia (Oreochromis niloticus). Anat. Rec. 2009, 292, 1780-1800. [CrossRef]

55. Holtzinger, A.; Evans, T. Gata4 regulates the formation of multiple organs. Development 2005, 132, 4005-4014. [CrossRef]

56. Albalat, R.; Baquero, M.; Minguillon, C. Identification and characterisation of the developmental expression pattern of tbx5b, a novel tbx5 gene in zebrafish. Gene Expr. Patterns 2010, 10, 24-30. [CrossRef] [PubMed]

57. Kudoh, T.; Tsang, M.; Hukriede, N.A.; Chen, X.F.; Dedekian, M.; Clarke, C.J.; Kiang, A.; Schultz, S.; Epstein, J.A.; Toyama, R.; et al. A gene expression screen in zebrafish embryogenesis. Genome Res. 2001, 11, 1979-1987. [CrossRef] [PubMed]

58. Schwartz, R.; Dayhoff, M.O. Matrices for Detecting Distant Relationships. In Atlas of Protein Sequences; Dayhoff, M., Ed.; National Biomedical Research Foundation: Washington, DC, USA, 1979; pp. 353-358.

59. Minko, K.; Bollerot, K.; Drevon, C.; Hallais, M.F.; Jaffredo, T. From mesoderm to blood islands: Patterns of key molecules during yolk sac erythropoiesis. Gene Expr. Patterns 2003, 3, 261-272. [CrossRef] 
60. Silver, L.; Palis, J. Initiation of murine embryonic erythropoiesis: A spatial analysis. Blood 1997, 89, 1154-1164. [CrossRef] [PubMed]

61. Chapman, D.L.; Garvey, N.; Hancock, S.; Alexiou, M.; Agulnik, S.I.; Gibson-Brown, J.J.; Cebra-Thomas, J.; Bollag, R.J.; Silver, L.M.; Papaioannou, V.E. Expression of the T-box family genes, Tbx1-Tbx5, during early mouse development. Dev. Dyn. 1996, 206, 379-390. [CrossRef]

62. Gibson-Brown, J.J.; Agulnik, S.I.; Silver, L.M.; Papaioannou, V.E. Expression of T-box genes Tbx2-Tbx5 during chick organogenesis. Mech. Dev. 1998, 74, 165-169. [CrossRef]

63. Gruenauer-Kloevekorn, C.; Reichel, M.B.; Duncker, G.I.W.; Froster, U.G. Molecular Genetic and Ocular Findings in Patients with Holt-Oram Syndrome. Ophthalmic Genet. 2005, 26, 1-8. [CrossRef]

64. Jones, D.T.; Taylor, W.R.; Thornton, J.M. The rapid generation of mutation data matrices from protein sequences. Bioinformatics 1992, 8, 275-282. [CrossRef]

65. Ranganayakulu, G.; Zhao, B.; Dokidis, A.; Molkentin, J.D.; Olson, E.N.; Schulz, R.A. A Series of Mutations in the D-MEF2 Transcription Factor Reveal Multiple Functions in Larval and Adult Myogenesis in Drosophila. Dev. Biol. 1995, 171, 169-181. [CrossRef]

66. Hinits, Y.; Pan, L.; Walker, C.; Dowd, J.; Moens, C.B.; Hughes, S.M. Zebrafish Mef2ca and Mef2cb are essential for both first and second heart field cardiomyocyte differentiation. Dev. Biol. 2012, 369, 199-210. [CrossRef] [PubMed]

67. Della Gaspera, B.; Armand, A.S.; Sequeira, I.; Lecolle, S.; Gallien, C.L.; Charbonnier, F.; Chanoine, C. The Xenopus MEF2 gene family: Evidence of a role for XMEF2C in larval tendon development. Dev. Biol. 2009, 328, 392-402. [CrossRef] [PubMed]

68. Brand-Saberi, B.; Christ, B. Evolution and development of distinct cell lineages derived from somites. Curr. Top. Dev. Biol. 2000, 48, 1-42. [CrossRef]

69. Reiter, J.F.; Alexander, J.; Rodaway, A.; Yelon, D.; Patient, R.; Holder, N.; Stainier, D.Y.R. Gata5 is required for the development of the heart and endoderm in zebrafish. Genes Dev. 1999, 13, 2983-2995. [CrossRef] [PubMed]

70. Schoenebeck, J.J.; Keegan, B.R.; Yelon, D. Vessel and blood specification override cardiac potential in anterior mesoderm. Dev. Cell 2007, 13, 254-267. [CrossRef]

71. Latinkic, B.V.; Kotecha, S.; Mohun, T.J. Induction of cardiomyocytes by GATA4 in Xenopus ectodermal explants. Development 2003, 130, 3865-3876. [CrossRef]

72. Garg, V.; Kathiriya, I.S.; Barnes, R.; Schluterman, M.K.; King, I.N.; Butler, C.A.; Rothrock, C.R.; Eapen, R.S.; Hirayama-Yamada, K.; Joo, K.; et al. GATA4 mutations cause human congenital heart defects and reveal an interaction with TBX5. Nature 2003, 424, 443-447. [CrossRef]

73. Rajagopal, S.K.; Ma, Q.; Obler, D.; Shen, J.; Manichaikul, A.; Tomita-Mitchell, A.; Boardman, K.; Briggs, C.; Garg, V.; Srivastava, D.; et al. Spectrum of heart disease associated with murine and human GATA4 mutation. J. Mol. Cell. Cardiol. 2007, 43, 677-685. [CrossRef]

74. Peterkin, T.; Gibson, A.; Patient, R. Redundancy and evolution of GATA factor requirements in development of the myocardium. Dev. Biol. 2007, 311, 623-635. [CrossRef]

75. Dobrzycki, T.; Lalwani, M.; Telfer, C.; Monteiro, R.; Patient, R. The roles and controls of GATA factors in blood and cardiac development. IUBMB Life 2019, 72, 39-44. [CrossRef]

76. Ciau-Uitz, A.; Monteiro, R.; Kirmizitas, A.; Patient, R. Developmental hematopoiesis: Ontogeny, genetic programming and conservation. Exp. Hematol. 2014, 42, 669-683. [CrossRef] [PubMed]

77. Bertrand, J.Y.; Chi, N.C.; Santoso, B.; Teng, S.; Stainier, D.Y.R.; Traver, D. Haematopoietic stem cells derive directly from aortic endothelium during development. Nature 2010, 464, 108-111. [CrossRef] [PubMed]

78. Gore, A.V.; Pillay, L.M.; Galanternik, M.V.; Weinstein, B.M. The zebrafish: A fintastic model for hematopoietic development and disease. Wiley Interdiscip. Rev. Dev. Biol. 2018, 7, e312. [CrossRef] [PubMed]

79. Dzierzak, E. The emergence of definitive hematopoietic stem cells in the mammal. Curr. Opin. Hematol. 2005, 12, 197-202. [CrossRef]

80. Cumano, A.; Godin, I. Ontogeny of the hematopoietic system. Annu. Rev. Immunol. 2007, 25, 745-785. [CrossRef]

81. Johnson, G.R.; Moore, M.A.S. Role of stem cell migration in initiation of mouse foetal liver haemopoiesis. Nature 1975, 258, 726-728. [CrossRef]

82. Houssaint, E. Differentiation of the mouse hepatic primordium. II. Extrinsic origin of the haemopoietic cell line. Cell Differ. 1981, 10, 243-252. [CrossRef] 
83. Keller, G.; Lacaud, G.; Robertson, S. Development of the hematopoietic system in the mouse. Exp. Hematol. 1999, 27, 777-787. [CrossRef]

84. Murayama, E.; Kissa, K.; Zapata, A.; Mordelet, E.; Briolat, V.; Lin, H.-F.; Handin, R.I.; Herbomel, P. Tracing hematopoietic precursor migration to successive hematopoietic organs during zebrafish development. Immunity 2006, 25, 963-975. [CrossRef]

85. Wolf, A.; Aggio, J.; Campbell, C.; Wright, F.; Marquez, G.; Traver, D.; Stachura, D.L. Zebrafish Caudal Haematopoietic Embryonic Stromal Tissue (CHEST) Cells Support Haematopoiesis. Sci. Rep. 2017, 7, 44644. [CrossRef]

86. Ueno, H.; Weissman, I.L. The origin and fate of yolk sac hematopoiesis: Application of chimera analyses to developmental studies. Int. J. Dev. Biol. 2010, 54, 1019-1031. [CrossRef] [PubMed]

87. Ferkowicz, M.J.; Yoder, M.C. Blood island formation: Longstanding observations and modern interpretations. Exp. Hematol. 2005, 33, 1041-1047. [CrossRef]

88. Detrich, H.W.; Kieran, M.W.; Chan, F.Y.; Barone, L.M.; Yee, K.; Rundstadler, J.A.; Pratt, S.; Ransom, D.; Zon, L.I. Intraembryonic hematopoietic cell migration during vertebrate development. Proc. Natl. Acad. Sci. USA 1995, 92, 10713-10717. [CrossRef] [PubMed]

89. Aronson, B.E.; Stapleton, K.A.; Krasinski, S.D. Role of GATA factors in development, differentiation, and homeostasis of the small intestinal epithelium. Am. J. Physiol. Liver Physiol. Liver Physiol. 2014, 306, G474-G490. [CrossRef] [PubMed]

90. Pevny, L.; Simon, M.C.; Robertson, E.; Klein, W.H.; Tsai, S.-F.; D’Agati, V.; Orkin, S.H.; Costantini, F. Erythroid differentiation in chimaeric mice blocked by a targeted mutation in the gene for transcription factor GATA-1. Nature 1991, 349, 257-260. [CrossRef]

91. Tsai, F.-Y.; Keller, G.; Kuo, F.C.; Weiss, M.; Chen, J.; Rosenblatt, M.; Alt, F.W.; Orkin, S.H. An early haematopoietic defect in mice lacking the transcription factor GATA-2. Nature 1994, 371, 221-226. [CrossRef]

92. Weiss, M.J.; Keller, G.; Orkin, S.H. Novel insights into erythroid development revealed through in vitro differentiation of GATA-1 embryonic stem cells. Genes Dev. 1994, 8, 1184-1197. [CrossRef]

93. Bruneau, B.G.; Nemer, G.; Schmitt, J.P.; Charron, F.; Robitaille, L.; Caron, S.; Conner, D.A.; Gessler, M.; Nemer, M.; Seidman, C.E.; et al. A murine model of Holt-Oram syndrome defines roles of the T-box transcription factor Tbx5 in cardiogenesis and disease. Cell 2001, 106, 709-721. [CrossRef]

94. Garrity, D.M.; Childs, S.; Fishman, M.C. The heartstrings mutation in zebrafish causes heart/fin Tbx5 deficiency syndrome. Development 2002, 129, 4635-4645.

95. Mommersteeg, M.T.M.; Soufan, A.T.; de Lange, F.J.; van den Hoff, M.J.B.; Anderson, R.H.; Christoffels, V.M.; Moorman, A.F.M. Two distinct pools of mesenchyme contribute to the development of the atrial septum. Circ. Res. 2006, 99, 351-353. [CrossRef]

96. Xie, L.; Hoffmann, A.D.; Burnicka-Turek, O.; Friedland-Little, J.M.; Zhang, K.; Moskowitz, I.P. Tbx5-Hedgehog Molecular Networks Are Essential in the Second Heart Field for Atrial Septation. Dev. Cell 2012, 23, 280-291. [CrossRef] [PubMed]

97. Zhu, Y.; Gramolini, A.O.; Walsh, M.A.; Zhou, Y.-Q.; Slorach, C.; Friedberg, M.K.; Takeuchi, J.K.; Sun, H.; Henkelman, R.M.; Backx, P.H.; et al. Tbx5-dependent pathway regulating diastolic function in congenital heart disease. Proc. Natl. Acad. Sci. USA 2008, 105, 5519-5524. [CrossRef] [PubMed]

98. Pi-Roig, A.; Martin-Blanco, E.; Minguillon, C. Distinct tissue-specific requirements for the zebrafish tbx5 genes during heart, retina and pectoral fin development. Open Biol. 2014, 4, 140014. [CrossRef] [PubMed]

99. Koshiba-Takeuchi, K.; Takeuchi, J.K.; Matsumoto, K.; Momose, T.; Uno, K.; Hoepker, V.; Ogura, K.; Takahashi, N.; Nakamura, H.; Yasuda, K.; et al. Tbx5 and the retinotectum projection. Science 2000, 287, 134-137. [CrossRef]

100. Anderson, E.A.T.B.; Ho, R.K. A transcriptomics analysis of the Tbx5 paralogues in zebrafish. PLoS ONE 2018, 13, e0208766. [CrossRef]

101. Tamura, K.; Yonei-Tamura, S.; Belmonte, J.C.I. Differential expression of Tbx4 and Tbx5 in Zebrafish fin buds. Mech. Dev. 1999, 87, 181-184. [CrossRef]

102. Begemann, G.; Ingham, P.W. Developmental regulation of Tbx5 in zebrafish embryogenesis. Mech. Dev. 2000, 90, 299-304. [CrossRef]

103. Agarwal, P.; Wylie, J.N.; Galceran, J.; Arkhitko, O.; Li, C.; Deng, C.; Grosschedl, R.; Bruneau, B.G. Tbx5 is essential for forelimb bud initiation following patterning of the limb field in the mouse embryo. Development 2003, 130, 623-633. [CrossRef] 
104. Mercader, N. Early steps of paired fin development in zebrafish compared with tetrapod limb development. Dev. Growth Differ. 2007, 49, 421-437. [CrossRef]

105. Adachi, N.; Robinson, M.; Goolsbee, A.; Shubin, N.H. Regulatory evolution of Tbx5 and the origin of paired appendages. Proc.S Natl. Acad. Sci. USA 2016, 113, 10115-10120. [CrossRef]

106. Cunningham, T.J.; Lancman, J.J.; Berenguer, M.; Dong, P.D.S.; Duester, G. Genomic Knockout of Two Presumed Forelimb Tbx5 Enhancers Reveals They Are Nonessential for Limb Development. Cell Rep. 2018, 23, 3146-3151. [CrossRef] [PubMed]

107. Lin, Q.; Schwarz, J.; Bucana, C.; Olson, E.N. Control of mouse cardiac morphogenesis and myogenesis by transcription factor MEF2C. Science 1997, 276, 1404-1407. [CrossRef] [PubMed]

108. Verzi, M.P.; McCulley, D.J.; De Val, S.; Dodou, E.; Black, B.L. The right ventricle, outflow tract, and ventricular septum comprise a restricted expression domain within the secondary/anterior heart field. Dev. Biol. 2005, 287, 134-145. [CrossRef] [PubMed]

109. Vong, L.; Bi, W.; O'Connor-Halligan, K.E.; Li, C.; Cserjesi, P.; Schwarz, J.J. MEF2C is required for the normal allocation of cells between the ventricular and sinoatrial precursors of the primary heart field. Dev. Dyn. 2006, 235, 1809-1821. [CrossRef]

110. Materna, S.C.; Sinha, T.; Barnes, R.M.; van Bueren, K.L.; Black, B.L. Cardiovascular development and survival require Mef2c function in the myocardial but not the endothelial lineage. Dev. Biol. 2019, 445, 170-177. [CrossRef]

111. Hinits, Y.; Hughes, S.M. Mef2s are required for thick filament formation in nascent muscle fibres. Development 2007, 134, 2511-2519. [CrossRef]

112. Lazic, S.; Scott, I.C. Mef2cb regulates late myocardial cell addition from a second heart field-like population of progenitors in zebrafish. Dev. Biol. 2011, 354, 123-133. [CrossRef]

113. Ticho, B.S.; Stainier, D.Y.R.; Fishman, M.C.; Breitbart, R.E. Three zebrafish MEF2 genes delineate somitic and cardiac muscle development in wild-type and mutant embryos. Mech. Dev. 1996, 59, 205-218. [CrossRef]

114. Torgersen, J.S.; Takle, H.; Andersen, Ø. Differential spatial expression of mef2 paralogs during cardiac development in Atlantic cod (Gadus morhua). Comp. Biochem. Physiol. Part. B Biochem. Mol. Biol. 2011, 158, 181-187. [CrossRef]

115. Breitbart, R.E.; Liang, C.-s.; Smoot, L.B.; Laheru, D.A.; Mahdavi, V.; Nadal-Ginard, B. A fourth human MEF2 transcription factor, hMEF2D, is an early marker of the myogenic lineage. Development 1993, 118, 1095-1106.

116. Ganassi, M.; Badodi, S.; Polacchini, A.; Baruffaldi, F.; Hughes, S.M.; Hinits, Y.; Molinari, S. Distinct functions of alternatively spliced isoforms encoded by zebrafish mef2ca and mef2cb. Biochim. Et Biophy. Acta (BBA) 2014, 1839, 559-570. [CrossRef]

117. Pownall, M.E.; Gustafsson, M.K.; Emerson, C.P. Myogenic regulatory factors and the specification of muscle progenitors in vertebrate embryos. Annu. Rev. Cell Dev. Biol. 2002, 18, 747-783. [CrossRef] [PubMed]

118. Hinits, Y.; Osborn, D.P.S.; Hughes, S.M. Differential requirements for myogenic regulatory factors distinguish medial and lateral somitic, cranial and fin muscle fibre populations. Development 2009, 136, 403-414. [CrossRef] [PubMed]

119. Cole, N.J.; Currie, P.D. Insights from sharks: Evolutionary and developmental models of fin development. Dev. Dyn. 2007, 236, 2421-2431. [CrossRef] [PubMed]

120. Gross, M.K.; Moran-Rivard, L.; Velasquez, T.; Nakatsu, M.N.; Jagla, K.; Goulding, M. Lbx1 is required for muscle precursor migration along a lateral pathway into the limb. Development 2000, 127, 413-424.

121. Neyt, C.; Jagla, K.; Thisse, C.; Thisse, B.; Haines, L.; Currie, P.D. Evolutionary origins of vertebrate appendicular muscle. Nature 2000, 408, 82-86. [CrossRef]

122. Cinnamon, Y.; Kahane, N.; Kalcheim, C. Characterization of the early development of specific hypaxial muscles from the ventrolateral myotome. Development 1999, 126, 4305-4315.

123. Okamoto, E.; Kusakabe, R.; Kuraku, S.; Hyodo, S.; Robert-Moreno, A.; Onimaru, K.; Sharpe, J.; Kuratani, S.; Tanaka, M. Migratory appendicular muscles precursor cells in the common ancestor to all vertebrates. Nat. Ecol. Evol. 2017, 1, 1731-1736. [CrossRef]

(C) 2020 by the authors. Licensee MDPI, Basel, Switzerland. This article is an open access article distributed under the terms and conditions of the Creative Commons Attribution (CC BY) license (http://creativecommons.org/licenses/by/4.0/). 